\title{
Dynamic modeling and transient stability analysis of distributed generators in a microgrid system
}

\author{
Hamed Ahmadi, Qobad Shafiee, Hassan Bevrani \\ Smart/Micro Grids Research Center, University of Kurdistan, Iran
}

\begin{tabular}{ll}
\hline \hline Article Info & ABSTRACT \\
\cline { 2 - 3 } Article history: & $\begin{array}{l}\text { Increasing the penetration level of distributed generation units as well as } \\
\text { power electronic devices adds more complexity and variability to the } \\
\text { dynamic behaviour of the microgrids. For such systems, studying the } \\
\text { transient modelling and stability is essential. One of the major disadvantages } \\
\text { Revised Feb 1, 2021 } \\
\text { Accepted Mar 4, } 2021 \\
\text { of most studies on microgrid modelling is their excessive attention to the } \\
\text { steady state period and the lack of attention to microgrid performance during } \\
\text { the transient period. In most of the research works, the behaviour of different } \\
\text { microgrid loads has not been studied. One of the mechanisms of power } \\
\text { systems stability studies is the application of state space modelling. This } \\
\text { paper presents a mathematical model for connected inverters in microgrid } \\
\text { systems with many variations of operating conditions. Nonlineal tools, } \\
\text { phase-plane trajectory analysis, and Lyapunov method were employed to } \\
\text { evaluate the limits of small signal models. Based on the results of the present } \\
\text { Nicrogrid model } \\
\text { Tranlinear model applying the model allows for the analysis of the system when } \\
\text { subjected to a severe transient disturbance such as loss of large load or } \\
\text { generation. Studying the transient stability of microgrid systems in the stand- } \\
\text { alone utility grid is useful and necessary for improving the design of the } \\
\text { microgrid's architecture. }\end{array}$
\end{tabular}

This is an open access article under the CC BY-SA license.

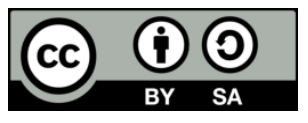

\section{Corresponding Author:}

Hamed Ahmadi

Smart/Micro Grids Research Center

University of Kurdistan

Pasdaran St, Sanandaj, Kurdistan, Iran

Email: h.ahmadi@eng.uok.ac.ir

\section{INTRODUCTION}

Intelligent microgrids integrate different energy resources, especially renewable ones, to provide dependable and efficient operations while being connected to the grid or islanding mode. It can ensure an uninterrupted reliable flow of power and economic and environmental benefits while minimizing the energy loss through transmission over long distances. Local power generation and storage systems make the operation of grid and critical facilities possible independent of the public utility when necessary, thus eliminating blackouts. New technologies provide the option of automatic fixing in case of necessity and anticipate power disturbances [1]-[4]. Microgrids can also feed the public utility when power demand and cost are the highest by supplying electricity from renewable sources. Thus, the use of intelligent power interfaces between the renewable source and the grid is required. These interfaces have a final stage consisting of dc/ac inverters, which can be classified into current source inverters (CSIs) and voltage-source inverters (VSIs). Although CSIs are commonly used to inject current into the grid, for island or autonomous operation, VSIs are needed to maintain voltage stability [5]-[10]. Moreover, a system without master control of inverters is advantageous where every inverter is able to change voltage and frequency of the microgrid in 
function of the PQ power into the microgrid. Besides, the fault of an inverter does not cause the collapse of the microgrid. In fact, each inverter could act as a plug-and-play entity to make expanding the microgrid system easier. Although the relationship between inverters is not necessary for the stability of the microgrid, it can be used to improve its performance [11]-[14].

Fast and flexible control of active and reactive power is an important requirement during the steady state and transient operation of the microgrid. A microgrid can experience low voltage instability when all distributed generation units are rotary machines with slow response speeds. Most of existing DG module technologies require power electronics converters as the intermediate interface in order to be connected to the network. A power electronics converter equipped with a quick control strategy can dynamically improve the microgrid stability by adjusting the instantaneous and reactive power, thereby increasing voltage quality and reducing the risk of angle instability. Due to different dynamics of distributed generator types compared to large power plants, the presence of distributed generation affects the dynamic characteristics of the grid. For this reason, modeling and controlling the behavior of these generators require careful consideration. This is more important in microgrids such that because of their small capacity, a distributed generation source can supply a significant percentage of load and its dynamic behavior greatly affects voltage and frequency control [15]-[17]. In [18] discusses the low voltage hybrid AC-DC microgrids power flow in islanding operation. The model simulation of hybrid AC-DC microgrid model have been carried out in two different cases, power flow from DC to AC sub microgrids and power flow from AC to DC sub microgrids. The result of the simulation shows that the model has a good response to power changes conditions.

In [19]-[21], appropriate simulation models and methods for investigating the dynamics of microgrids in transient stability have been developed. In the mentioned study, the aim is to investigate the interaction of microgrids in connected and islanded operation modes. All the components of the microgrids are modeled with sources, loads, lines, and power electronic interfaces.

This paper works with both lineal and nonlineal tools. It uses phase-plane trajectory analysis and a method of Lyapunov to determine large variations in the systems. It is suggested that the new proposed model be utilized to analyze the system when it is subject to a severe transient disturbance, such as the loss of large loads or generation. In this paper, first, the mathematical model of the microgrid and basic equations are presented. Then, the system is described. The next step is the study of stability of Lyapunov. Finally, some simulations are presented.

\section{MATHEMATICAL MODEL}

Figure 1 presents a microgrid system in a stand-alone mode based on parallel connected inverters. It is assumed that the system is a balanced three-phase circuit. Each generator has a power DC renewable source, a DC/AC inverter, and a low pass filter and it is managed by two control loops. An inner loop is used to regulate the output voltage and current and the outer loop is used to share and trade-off the PQ power in the microgrid without communication between generators. This model does not consider the dynamics of the inner loop because it is of high frequency type [22]-[24].

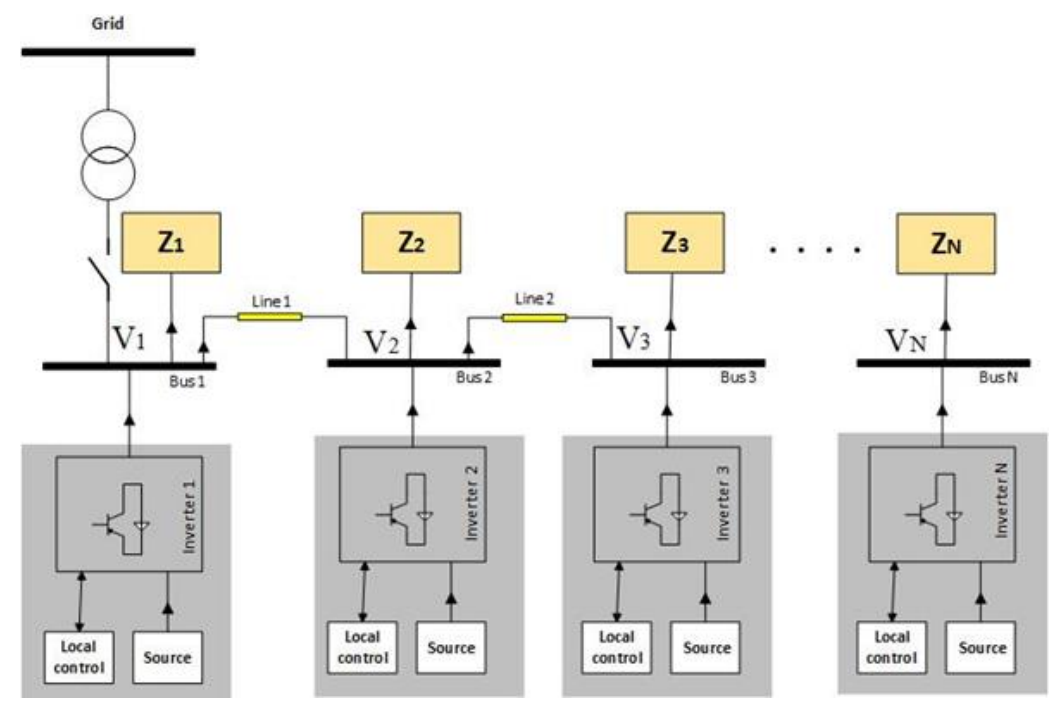

Figure 1. Typical structure of inverter-based microgrid 
For systems with two inverters connected, the signals can be represented as (1), (2):

$$
\begin{aligned}
& V_{1}=\left|V_{1}\right| e^{j \theta_{1}}, V_{2}=\left|V_{2}\right| e^{j \theta_{2}}, \ldots, V_{i}=\left|V_{i}\right| e^{j \theta_{i}}, V_{i+1}=\left|V_{i+1}\right| e^{j \theta_{i+1}} \\
& \theta_{1}=\operatorname{Arctan}\left(\frac{v_{q 1}}{v_{d 1}}\right), \theta_{2}=\operatorname{Arctan}\left(\frac{v_{q 2}}{v_{d 2}}\right), \ldots, \theta_{i}=\operatorname{Arctan}\left(\frac{v_{q i}}{v_{d i}}\right)
\end{aligned}
$$

and

$$
\theta_{i, i+1}=\theta_{i}-\theta_{i+1}
$$

Where $\mathrm{V}_{\mathrm{i}}$ is nominal set points of $\mathrm{d}$-axis output voltage, $\theta_{i}$ is the power angle of the $\mathrm{i}$ 'th generator, $\theta_{i \cdot i+1}$ is the power angle between $\mathrm{i}$ and $\mathrm{i}+1$ 'th generators, $\mathrm{v}_{\mathrm{di}}$ and $\mathrm{v}_{\mathrm{qi}}$ are output voltages of the $\mathrm{i}$-th islanded-inverter distributed in $\mathrm{d}$-axis and q-axis respectively. The derived power angle between both generators can be defined by (4):

$$
\dot{\theta}_{i, i+1}=\omega_{i}-\omega_{i+1}
$$

$\omega_{\mathrm{i}}$ is stator supply angular frequency.

The PQ controller uses an artificial droop control scheme with average signals $\mathrm{P}$ and $\mathrm{Q}$, which are obtained using the low-pass filter, that can be expressed as (5), (6):

$$
\begin{aligned}
& \omega_{i}=\omega_{0}-k_{p} P \\
& V_{i}=V_{0}-k_{v} Q
\end{aligned}
$$

where, $\omega_{0}$ and $\mathrm{V}_{0}$ are system rated speed and voltage, $\mathrm{P}$ and $\mathrm{Q}$ are active and reactive average power respectively, also $\mathrm{K}_{\mathrm{p}}$ and $\mathrm{K}_{\mathrm{v}}$ are droop coefficients.

The cut-off frequency $\left(\omega_{f}\right)$ used in (7) and (8) is a decade lower than frequency of the microgrid.

$$
\begin{gathered}
P=\frac{\omega_{f}}{s+\omega_{f}} P_{i} \\
Q=\frac{\omega_{f}}{s+\omega_{f}} Q_{i}
\end{gathered}
$$

That, $\mathrm{P}_{\mathrm{i}}$ and $\mathrm{Q}_{\mathrm{i}}$ are instantaneous power. If (7) and (8) are replaced in (5) and (6),

$$
\begin{gathered}
\omega_{i}=\omega_{0}-k_{p} \frac{\omega_{f}}{s+\omega_{f}} P_{i} \\
V_{i}=V_{0}-k_{v} \frac{\omega_{f}}{s+\omega_{f}} Q_{i}
\end{gathered}
$$

It is possible to rewrite the curve droop equation and the low pass filter in the time domain as in (11), and (12):

$$
\begin{aligned}
& \dot{\omega}_{i}=-\omega_{f} \omega_{i}+\omega_{f} \omega_{0}-k_{p} \omega_{f} P_{i} \\
& \dot{V}_{i}=-\omega_{f} V_{i}+\omega_{f} V_{0}-k_{v} \omega_{f} Q_{i}
\end{aligned}
$$

For primary and end inverters connected (with index i): 


$$
\begin{aligned}
& P_{i}=\frac{R_{i}}{R_{i}^{2}+X_{i}^{2}} V_{i}^{2}-\frac{V_{i} V_{i+1}}{X_{i, i+1}} \operatorname{Sin}\left(\theta_{i, i+1}\right) \\
& Q_{i}=\frac{X_{i}}{R_{i}^{2}+X_{i}^{2}} V_{i}^{2}+\frac{V_{i}^{2}}{X_{i, i+1}}-\frac{V_{i} V_{i+1}}{X_{i, i+1}} \operatorname{Cos}\left(\theta_{i, i+1}\right)
\end{aligned}
$$

where, $R_{i}$ and $X_{i}$ are resistor and inductance of $i$ 'th generator, also $X_{i, i+1}$.is line inductance between $i$ and $i+1$ 'th inverters.

Replacing (13) and (14) in (11) and (12), we will have:

$$
\begin{aligned}
& \dot{\omega}_{i}=-\omega_{f} \omega_{i}+\omega_{f} \omega_{0}-\frac{k_{p} \omega_{f} R_{i}}{R_{i}^{2}+X_{i}^{2}} V_{i}^{2}+\frac{k_{p} \omega_{f}}{X_{i, i+1}} V_{i} V_{i+1} \operatorname{Sin}\left(\theta_{i, i+1}\right) \\
& \dot{V}_{i}=-\omega_{f} V_{i}+\omega_{f} V_{0}-\left(\frac{k_{v} \omega_{f} X_{i}}{R_{i}^{2}+X_{i}^{2}}-\frac{k_{v} \omega_{f}}{X_{i, i+1}}\right) V_{i}^{2}+\frac{k_{v} \omega_{f}}{X_{i, i+1}} V_{i} V_{i+1} \operatorname{Cos}\left(\theta_{i, i+1}\right)
\end{aligned}
$$

For inner inverter connected (with index m):

$$
\begin{aligned}
& P_{m}=\frac{R_{m}}{R_{m}^{2}+X_{m}^{2}} V_{m}^{2}-\frac{V_{m-1} V_{m}}{X_{m-1, m}} \operatorname{Sin}\left(\theta_{m-1, m}\right)+\frac{V_{m} V_{m+1}}{X_{m, m+1}} \operatorname{Sin}\left(\theta_{m, m+1}\right) \\
& Q_{m}=\frac{X_{m}}{R_{m}^{2}+X_{m}^{2}} V_{m}^{2}+\frac{V_{m}^{2}}{X_{m-1, m}}-\frac{V_{m-1} V_{m}}{X_{m-1, m}} \operatorname{Cos}\left(\theta_{m-1, m}\right) \\
& -\frac{V_{m}^{2}}{X_{m, m+1}}+\frac{V_{m} V_{m+1}}{X_{m, m+1}} \operatorname{Cos}\left(\theta_{m, m+1}\right)
\end{aligned}
$$

Replacing (17) and (18) in (11) and (12), we will have:

$$
\begin{aligned}
& \dot{\omega}_{m}=-\omega_{f} \omega_{m}+\omega_{f} \omega_{0}-\frac{k_{p} \omega_{f} R_{m}}{R_{m}^{2}+X_{m}^{2}} V_{m}^{2} \\
& +\frac{k_{p} \omega_{f}}{X_{m-1, m}} V_{m-1} V_{m} \operatorname{Sin}\left(\theta_{m-1, m}\right)-\frac{k_{p} \omega_{f}}{X_{m, m+1}} V_{m} V_{m+1} \operatorname{Sin}\left(\theta_{m, m+1}\right) \\
& \dot{V}_{m}=-\omega_{f} V_{m}+\omega_{f} V_{0}-\left(\frac{k_{v} \omega_{f} X_{m}}{R_{m}^{2}+X_{m}^{2}}+\frac{k_{v} \omega_{f}}{X_{m-1, m}}-\frac{k_{v} \omega_{f}}{X_{m, m+1}}\right) V_{m}^{2} \\
& +\frac{k_{v} \omega_{f}}{X_{m-1, m}} V_{m-1} V_{m} \operatorname{Cos}\left(\theta_{m-1, m}\right)-\frac{k_{v} \omega_{f}}{X_{m, m+1}} V_{m} V_{m+1} \operatorname{Cos}\left(\theta_{m, m+1}\right)
\end{aligned}
$$

\section{STUDY SYSTEM}

Figure 2 show the circuit diagram of the microgrid systems in the stand-alone mode considered in this paper. This system has two inverters connected and the assumption is based on small signal modeling.

It is assumed that

$$
X_{1}=\theta_{12}, X_{2}=\omega_{1}, X_{3}=\omega_{2}, X_{4}=\left|V_{1}\right|, X_{5}=\left|V_{2}\right|
$$

According to (4), (15), and (16), we get:

$$
\begin{aligned}
& \dot{X}_{1}=X_{2}-X_{3} \\
& \dot{X}_{2}=-\omega_{f} X_{2}+\omega_{f} \omega_{0}-\frac{k_{p} \omega_{f} R_{1}}{R_{1}^{2}+X_{1}^{2}} X_{4}^{2}+\frac{k_{p} \omega_{f}}{X_{1,2}} X_{4} X_{5} \operatorname{Sin}\left(X_{1}\right)
\end{aligned}
$$




$$
\begin{aligned}
& \dot{X}_{3}=-\omega_{f} X_{3}+\omega_{f} \omega_{0}-\frac{k_{p} \omega_{f} R_{2}}{R_{2}^{2}+X_{2}^{2}} X_{5}^{2}+\frac{k_{p} \omega_{f}}{X_{1,2}} X_{4} X_{5} \operatorname{Sin}\left(X_{1}\right) \\
& \dot{X}_{4}=-\omega_{f} X_{4}+\omega_{f} V_{0}-\left(\frac{k_{v} \omega_{f} X_{1}}{R_{1}^{2}+X_{1}^{2}}-\frac{k_{v} \omega_{f}}{X_{1,2}}\right) X_{4}^{2}+\frac{k_{v} \omega_{f}}{X_{1,2}} X_{4} X_{5} \operatorname{Cos}\left(X_{1}\right) \\
& \dot{X}_{5}=-\omega_{f} X_{5}+\omega_{f} V_{0}-\left(\frac{k_{v} \omega_{f} X_{2}}{R_{2}^{2}+X_{2}^{2}}-\frac{k_{v} \omega_{f}}{X_{1,2}}\right) X_{5}^{2}+\frac{k_{v} \omega_{f}}{X_{1,2}} X_{4} X_{5} \operatorname{Cos}\left(X_{1}\right)
\end{aligned}
$$

The system shown in Figure 2 has the parameters presented in Table 1. Thus:

$$
\begin{aligned}
& \dot{X}_{1}=X_{2}-X_{3} \\
& \dot{X}_{2}=-31.4 X_{2}+9.8 \times 10^{3}-2.8 \times 10^{-5} X_{4}^{2}-0.0027 X_{4} X_{5} \operatorname{Sin}\left(X_{1}\right) \\
& \dot{X}_{3}=-31.4 X_{3}+9.8 \times 10^{3}-3.4 \times 10^{-5} X_{5}^{2}+0.0027 X_{4} X_{5} \operatorname{Sin}\left(X_{1}\right) \\
& \dot{X}_{4}=-31.4 X_{4}+7.2 \times 10^{3}-0.0307 X_{4}^{2}+0.0307 X_{4} X_{5} \operatorname{Cos}\left(X_{1}\right) \\
& \dot{X}_{5}=-31.4 X_{5}+7.2 \times 10^{3}-0.0307 X_{5}^{2}+0.0307 X_{4} X_{5} \operatorname{Cos}\left(X_{1}\right)
\end{aligned}
$$

The equilibrium points can be obtained if they make all the derivatives of the system equal to zero:

$$
f(X)=0=\left\{\begin{array}{c}
0=X_{2}-X_{3} \\
0=-31.4 X_{2}+9.8 \times 10^{3}-2.8 \times 10^{-5} X_{4}^{2}-0.0027 X_{4} X_{5} \operatorname{Sin}\left(X_{1}\right) \\
0=-31.4 X_{3}+9.8 \times 10^{3}-3.4 \times 10^{-5} X_{5}^{2}+0.0027 X_{4} X_{5} \operatorname{Sin}\left(X_{1}\right) \\
0=-31.4 X_{4}+7.2 \times 10^{3}-0.0307 X_{4}^{2}+0.0307 X_{4} X_{5} \operatorname{Cos}\left(X_{1}\right) \\
0=-31.4 X_{5}+7.2 \times 10^{3}-0.0307 X_{5}^{2}+0.0307 X_{4} X_{5} \operatorname{Cos}\left(X_{1}\right)
\end{array}\right.
$$

Mathematical software was used to solve (32) and find the equilibrium points. An equilibrium point in the range of the state variables $\mathrm{X}_{5}$ is shown by (33):

$$
\begin{aligned}
X_{0} & =\left[\begin{array}{lllll}
X_{01} & X_{02} & X_{03} & X_{04} & X_{05}
\end{array}\right] \\
& =\left[\begin{array}{llllll}
0.0019 & 320.18 & 320.18 & 239.7 & 239.6
\end{array}\right]
\end{aligned}
$$

The stability of the equilibrium point, $X_{0}$, can be determined via linearization [25], [26] through the Jacobian matrix of $f(X)$ at the equilibrium point. The values of matrix A are:

$$
A=\left[\begin{array}{ccccc}
0 & 1 & -1 & 0 & 0 \\
-153.9 & -32.04 & 0 & -0.145 & -0.0009 \\
153.9 & 0 & -32.04 & -0.0009 & -0.0162 \\
-2.363 & 0 & 0 & -39.407 & 7.35 \\
-2.363 & 0 & 0 & 7.36 & -39.4
\end{array}\right]
$$

The respective eigenvalues are:

$$
\begin{aligned}
& \lambda_{1}=-16.02+i 7 \\
& \lambda_{2}=-16.02-i 7 \\
& \lambda_{3}=-32.05 \\
& \lambda_{4}=-46.8 \\
& \lambda_{5}=-32.05
\end{aligned}
$$

It is shown that all the real part of eigenvalues are negative. Consequently, the equilibrium point is stable for small signals. 


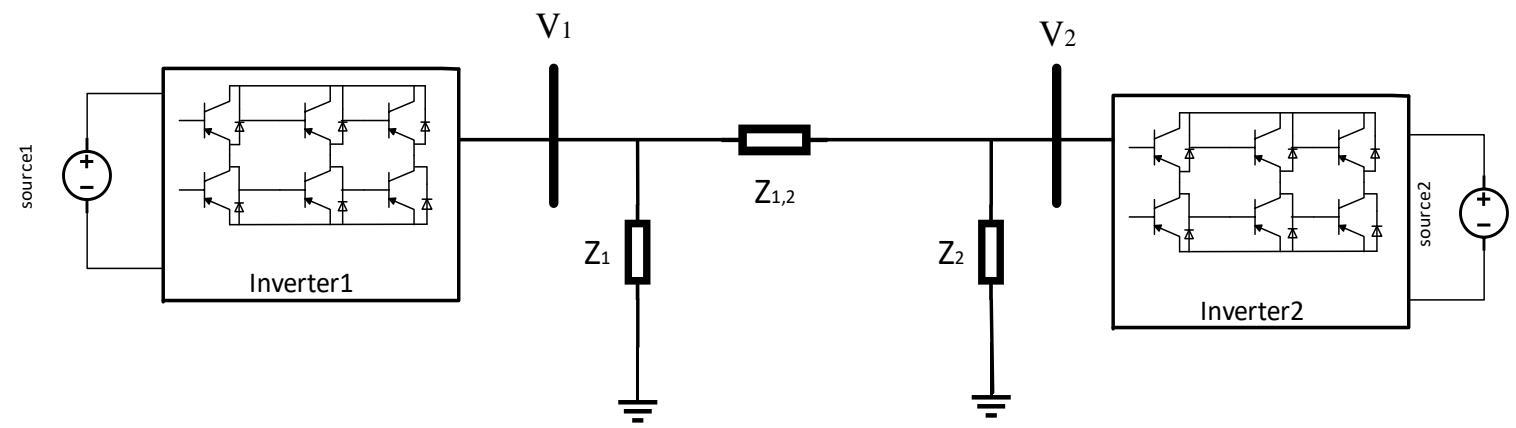

Figure 2. Parallel connected inverters in microgrid system operating in the stand-alone mode

Table 1. System parameters

\begin{tabular}{ccc}
\hline Variable & Value & Unit \\
\hline $\mathrm{V}_{\mathrm{o}}$ & 220 & $\mathrm{v}$ \\
$\mathrm{f}_{\mathrm{s}}$ & 50 & $\mathrm{~Hz}$ \\
$\mathrm{X}$ & 1.57 & $\Omega$ \\
$\mathrm{R}$ & 0.0012 & $\Omega$ \\
$\mathrm{R}_{1}$ & 150 & $\Omega$ \\
$\mathrm{X}_{1}$ & 3.14 & $\Omega$ \\
$\mathrm{R}_{2}$ & 120 & $\Omega$ \\
$\mathrm{X}_{2}$ & 15.7 & $\Omega$ \\
$\mathrm{K}_{\mathrm{p} 1}=\mathrm{K}_{\mathrm{p} 2}$ & 0.00013 & Rad.s- $1 / \mathrm{W}$ \\
$\mathrm{K}_{\mathrm{v} 1}=\mathrm{K}_{\mathrm{v} 2}$ & 0.0015 & V/VAR \\
$\boldsymbol{\omega}_{f}$ & 31.4 & $\mathrm{Rad} / \mathrm{s}$ \\
\hline
\end{tabular}

\section{STABILITY OF LYAPUNOV}

Variations in the angle, active power, and frequency of the first generator were analyzed and a negligible variation in the voltage was found. The second generator is an infinite bus with fixed frequency and voltage $\left(X_{1}=Y_{1}, X_{2}=Y_{2}, X_{3}=314 \mathrm{rad} / \mathrm{s}, X_{4}=Y_{3}, X_{5}=230 \mathrm{v}\right)$. The set of equations for the single generator is given by (36):

$$
f(Y)=\left\{\begin{array}{c}
\dot{Y}_{1}=Y_{2}-314 \\
\dot{Y}_{2}=-31.4 Y_{2}+9.8 \times 10^{3}-2.8 \times 10^{-5} Y_{3}^{2}-0.62 Y_{3} \operatorname{Sin}\left(Y_{1}\right) \\
\dot{Y}_{3}=-31.4 Y_{3}+7.2 \times 10^{3}-0.0307 Y_{3}^{2}+7.061 Y_{3} \operatorname{Cos}\left(Y_{1}\right)
\end{array}\right.
$$
$f(Y)=0$.

Equation (36) reaches the equilibrium point by the solution to the nonlinear algebraic equation

$$
Y_{0}=\left[\begin{array}{lll}
Y_{01} & Y_{02} & Y_{03}
\end{array}\right]=\left[\begin{array}{lll}
-0.01 & 314.1 & 229.9
\end{array}\right]
$$

For Lyapunov stability analysis, it is convenient to transfer the stable equilibrium point to the origin by the transformation $\mathrm{Z}=\mathrm{Y}-\mathrm{Y}_{0}$. Thus, (36) becomes:

$$
\left\{\begin{array}{c}
\dot{Z}_{1}=Z_{2} \\
\dot{Z}_{2}=-1.47-31.4 Z_{2}-2.8 \times 10^{-5} Z_{3}^{2}-0.01 Z_{3} \\
+0.006 Z_{3} \operatorname{Sin}\left(Z_{1}\right)-0.6 Z_{3} \operatorname{Cos}\left(Z_{1}\right)-140 \operatorname{Sin}\left(Z_{1}\right)+1.47 \operatorname{Cos}\left(Z_{1}\right) \\
\dot{Z}_{3}=-1.6 \times 10^{-3}-13.8 Z_{3}-0.03 Z_{3}^{2}-6.9 Z_{3} \operatorname{Cos}\left(Z_{1}\right) \\
+0.07 Z_{3} \operatorname{Cos}\left(Z_{1}\right)-140 \operatorname{Sin}\left(Z_{1}\right)+1.6 \times 10^{3} \operatorname{Cos}\left(Z_{1}\right)+16.6 \operatorname{Sin}\left(Z_{1}\right)
\end{array}\right.
$$

This study assumes that the system is working in the stable equilibrium point and there is a large variation in the angle $\left(Z_{1}\right)$. The voltage magnitude is constant. By working with the reduced model, we will have: 


$$
\begin{aligned}
& \dot{Z}_{1}=Z_{2} \\
& \dot{Z}_{2}=-31.4 Z_{2}-1.47-140 \operatorname{Sin}\left(Z_{1}\right)+1.47 \operatorname{Cos}\left(Z_{1}\right)
\end{aligned}
$$

The phase portrait shown in Figure 3 can also be used to analyze whether all the trajectories between 3 and -3 move towards the equilibrium point at the origin. By assuming that

$$
f\left(Z_{1}\right)=1.47+140 \operatorname{Sin}\left(Z_{1}\right)-1.47 \operatorname{Cos}\left(Z_{1}\right)
$$

Is a variable gradient method for constructing a Lyapunov function [27], [28] and if it is applied to (16), the Lyapunov function is:

$$
V\left(Z_{1}, Z_{2}\right)=\frac{1}{2}\left(31.4 Z_{1}+Z_{2}\right)^{2}+\int_{0}^{Z_{1}} f(u) d u
$$

Equation (41) can be transformed into

$$
\dot{V}\left(Z_{1}, Z_{2}\right)=-31.4 Z_{1} f\left(Z_{1}\right)
$$

The region of asymptotic stability is shown in Figure 4.

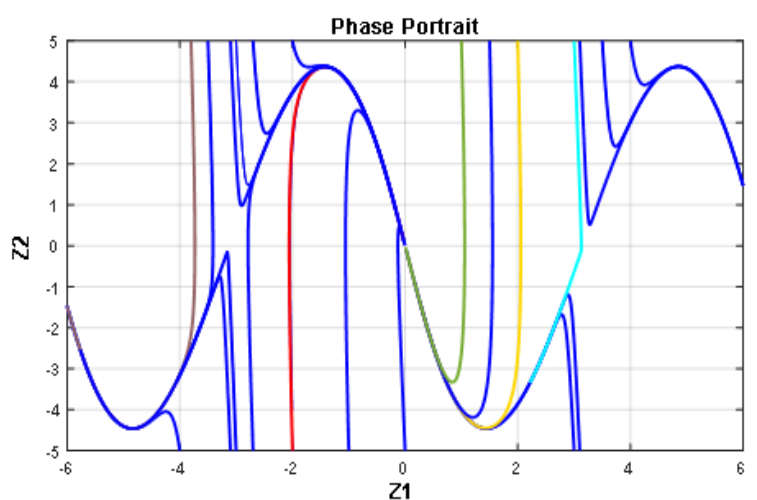

Figure 3. Phase portrait of $\mathrm{Z}_{1}-\mathrm{Z}_{2} .\left(\mathrm{x}=\mathrm{Z}_{1}, \mathrm{y}=\mathrm{Z}_{2}\right)$

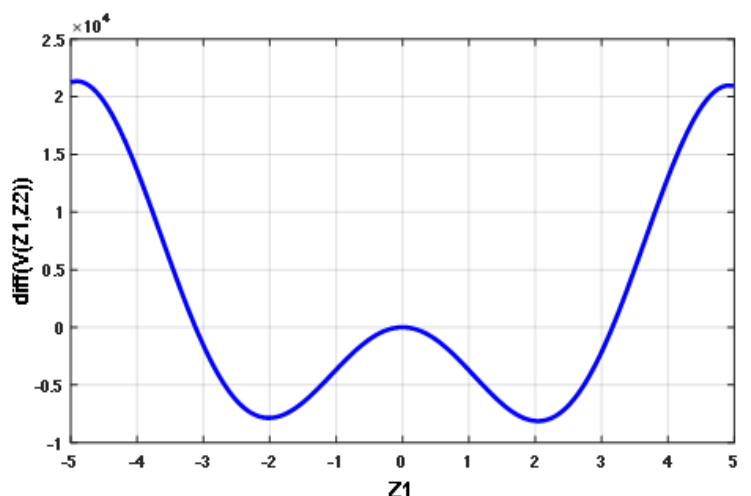

Figure 4. Derivate of Lyapunov function

\section{SIMULATION RESULTS}

The proposed microgrid is simulated in order to show the behavior of the systems, their equilibrium points, and the stability of the microgrid in general when there are possible changes in parameters. Figures 5 to 8 show the state variables of the systems. In this case, it is assumed that all the DG and impedance parameters given in Table 1 are involved. There are no faults during the operation. The simulation is repeated with a different line inductance values $(0.157 \Omega, 1 \Omega$, and $1.57 \Omega)$.

These figures have been carried out for verification of the nonlinear model of studied islandedinverter-based microgrid system using the proposed generalized modelling approach. The time-domain simulation results have been obtained by solving a nonlinear differential-algebraic system of equations using numerical integration methods. According to Figure 5 when the system begins, the angle between $V_{1}$ and $V_{2}$ is zero. It has a transient response and it reaches steady point. As the line impedance increases, the overshoot of angle decreases due to the damping of the oscillations.

Figures 9 to 12 show the active and reactive power to each generator with different line inductor values $(0.157 \Omega, 1 \Omega$, and $1.57 \Omega)$. The process by which the stability is affected when the line inductance decreases can be witnessed. According to Figures 9 to 10, it can be said that the active capacities produced by the DG units vary for each unit, because the nominal power of them considered unequal. This confirms that the division of active power between units is proportional to their nominal power. According to Figures 11 to 12 the reactive power produced by each DG unit is proportional to its nominal power, because of existence the high resistance line in a low or medium voltage microgrid leads to a current. 


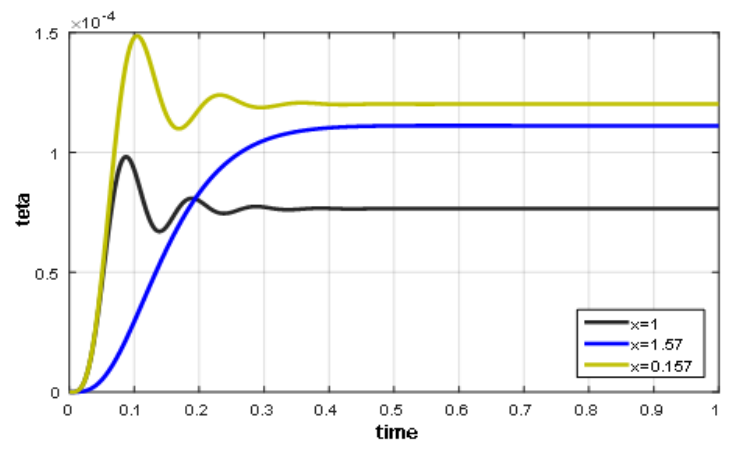

Figure 5. Angle between $V_{1}$ and $V_{2}$ when the line inductance is increased

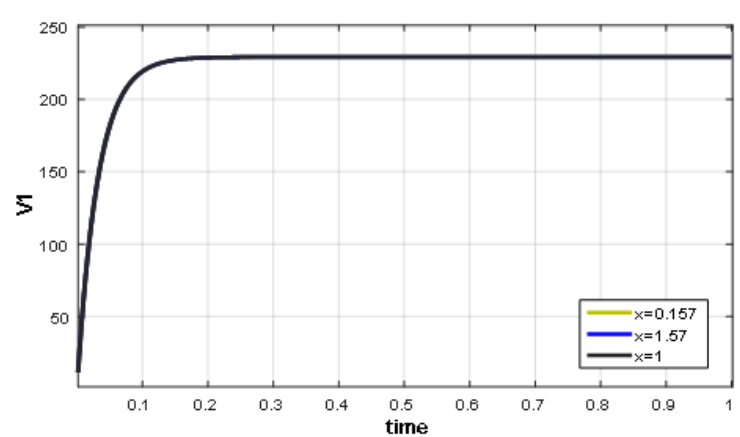

Figure 7. Voltage of bus 1 when the line inductance is increased

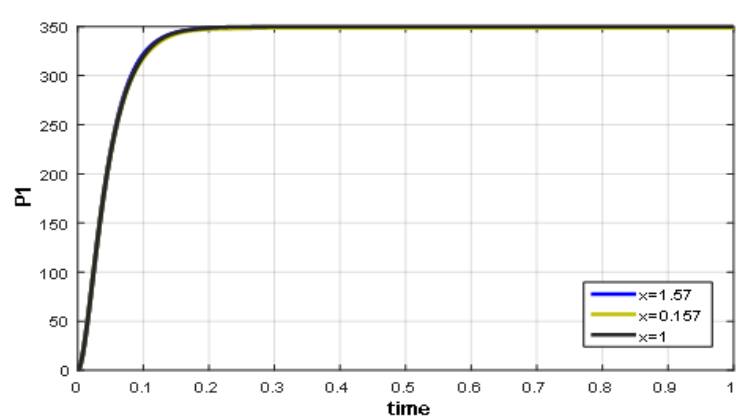

Figure 9. Active power of DG1 when the line inductance is increased

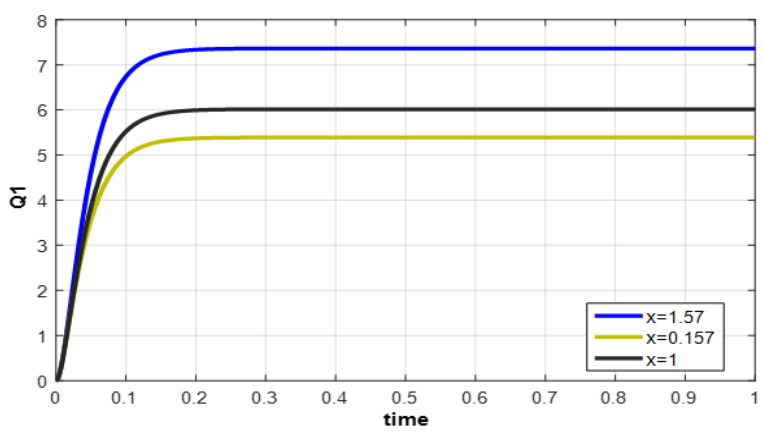

Figure 11. Reactive power of DG1 when the line inductance is increased

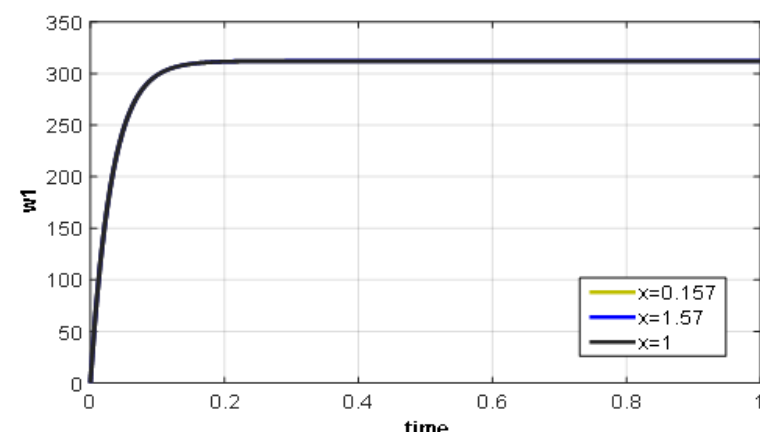

Figure 6. Angular frequency of DG1 when the line inductance is increased

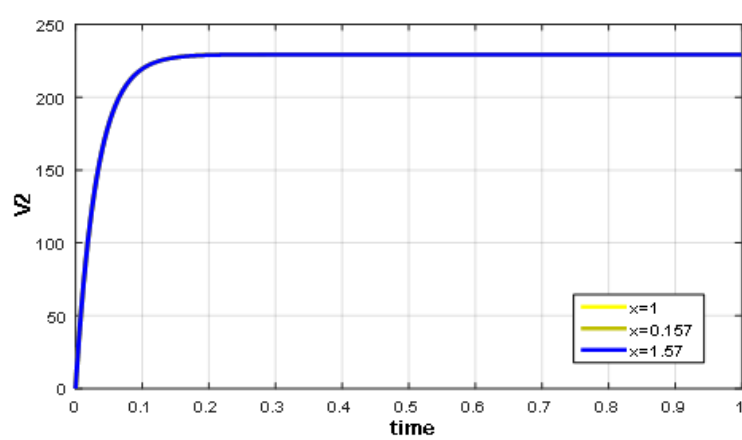

Figure 8 . Voltage of bus 2 when the line inductance is increased

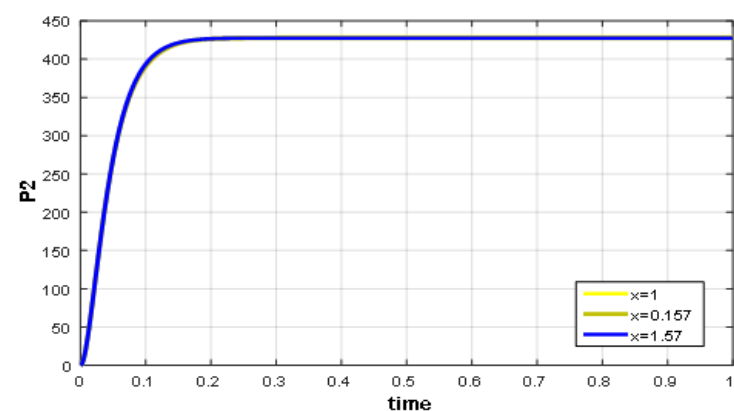

Figure 10. Active power of DG2 when the line inductance is increased

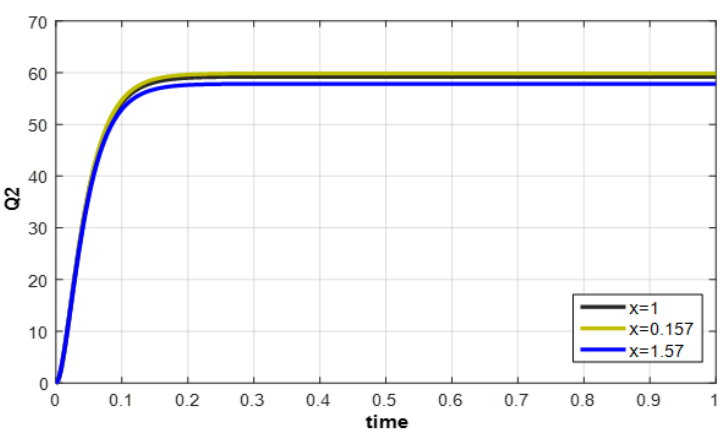

Figure 12. Reactive power of DG2 when the line inductance is increased 
Power sharing can be modified by choosing different droop controller gains. The eigenvalues analysis, on the other hand, predicts poor damping for huge droop controller gains. Figures 13 to 16 show the variations in the $\mathrm{P}$ and $\mathrm{Q}$ power to each generator when the $\mathrm{K}_{\mathrm{p}}$ coefficient is increased.

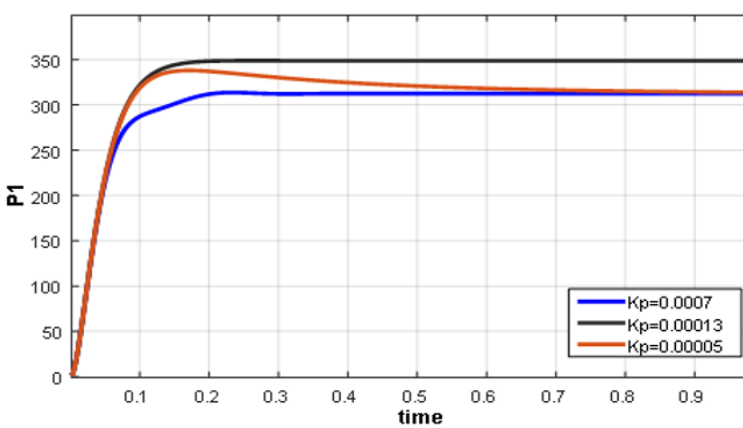

Figure 13. Active power of DG1 when the $\mathrm{K}_{\mathrm{p}}$ coefficient is increased

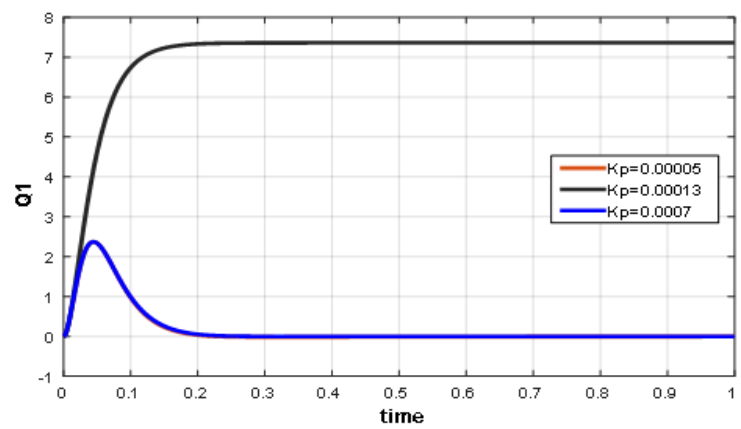

Figure 15. Reactive power of DG1 when the $\mathrm{K}_{\mathrm{p}}$ coefficient is increased

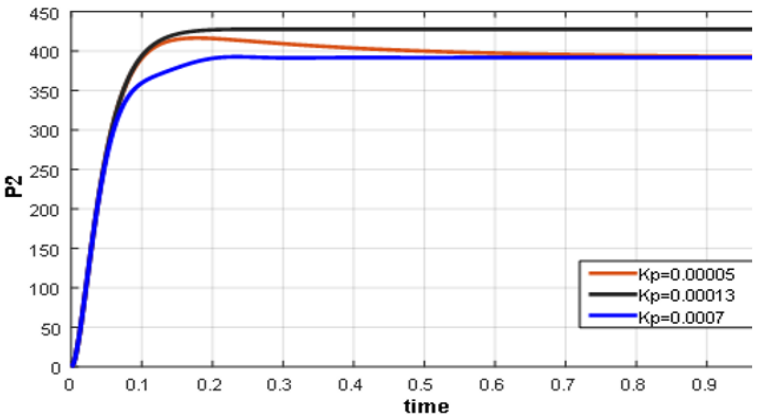

Figure 14. Active power of DG2 when the $\mathrm{K}_{\mathrm{p}}$ coefficient is increased

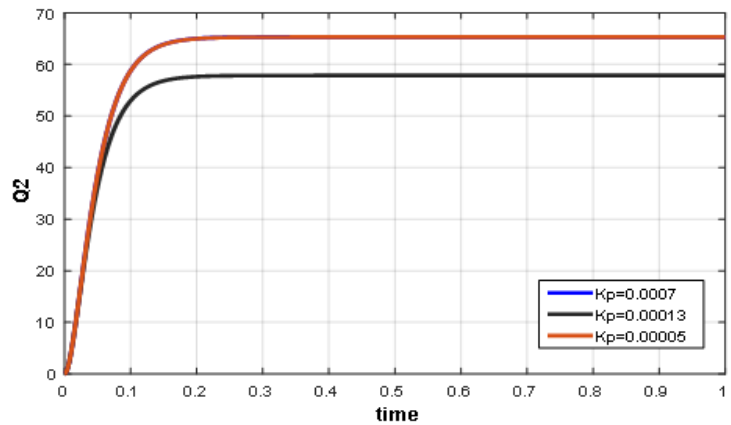

Figure 16. Reactive power of DG2 when the $\mathrm{K}_{\mathrm{p}}$ coefficient is increased

Figure 17 show large disturbance in $\mathrm{V}_{2}$. This disturbance occurs at time 2 (second) and it is 0.2 second long. The amplitude of disturbances is $20 \mathrm{v}$. The microgrid is recovered after that. Figures 18 to 23 show other parameters when disturbance occurs in $\mathrm{V}_{2}$. According to Figure 18 voltage of DG1 unit is almost constant. Figure 19 illustrate that during the time of disturbance, the angle between $\mathrm{V}_{1}$ and $\mathrm{V}_{2}$ oscillates due to changes in the voltage of the second bus. But the microgrid is recovered after the disturbance. According to Figures 20 and 21, it is observed that in the presence of voltage sag, the active power of both DG units are changed. But according to Figures 22 and 23, reactive power of DG2 reduced more than DG1, which indicates a direct dependence between voltage and reactive power.

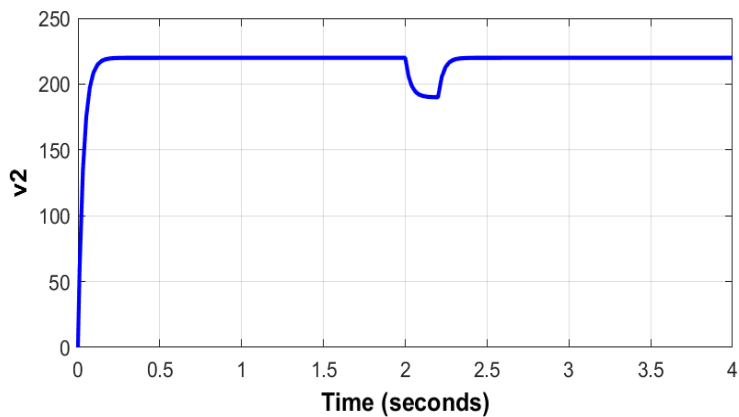

Figure 17. Voltage of bus2 when the disturbance occurs at $\mathrm{V}_{2}$

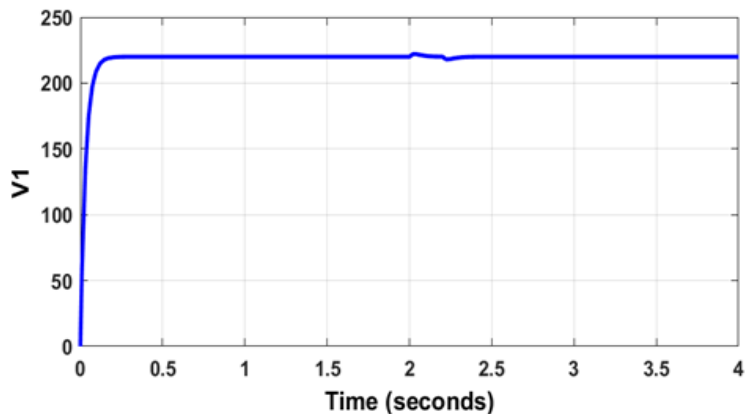

Figure 18. Voltage of bus1 when the disturbance occurs at $\mathrm{V}_{2}$ 


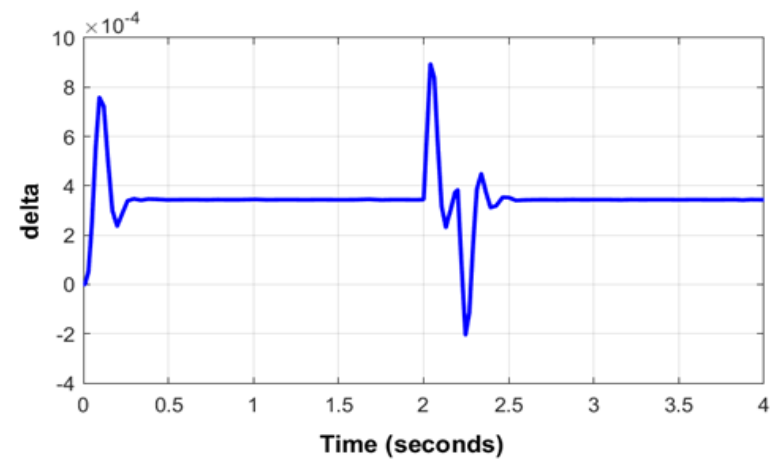

Figure 19. Angle between $V_{1}$ and $V_{2}$ when the disturbance occurs at $\mathrm{V}_{2}$

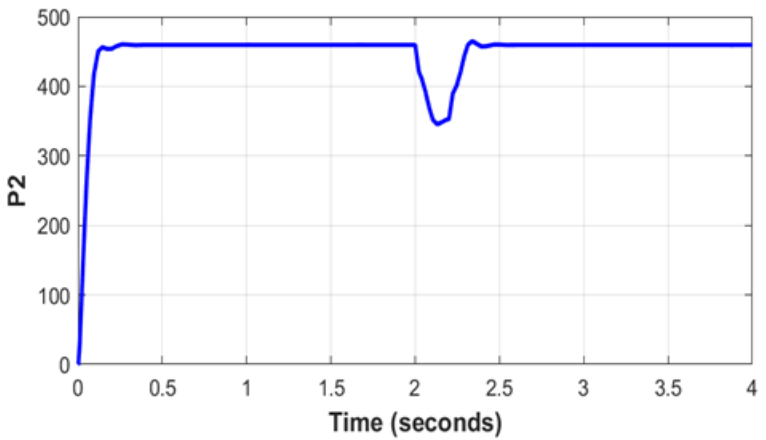

Figure 21. Active power of DG2 when the disturbance occurs at $\mathrm{V}_{2}$

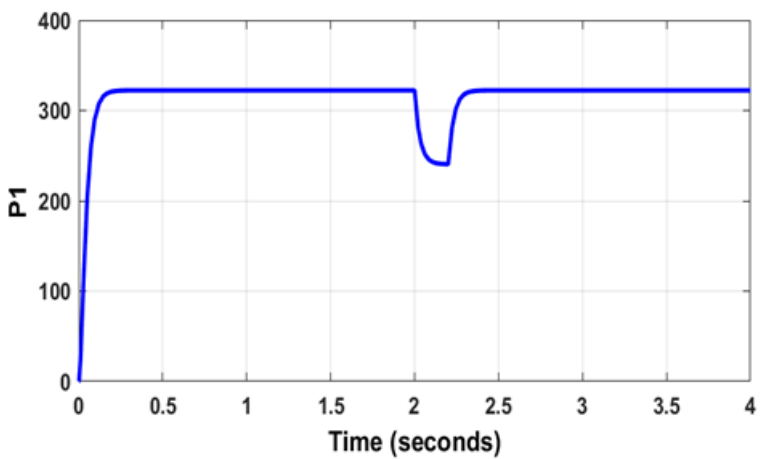

Figure 20. Active power of DG1 when the disturbance occurs at $\mathrm{V}_{2}$

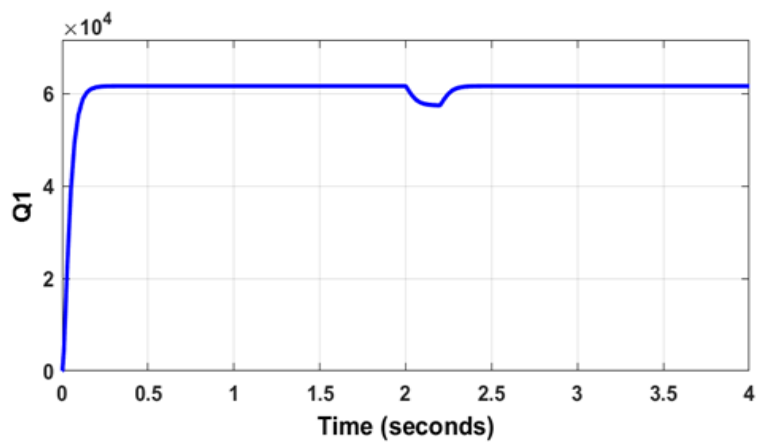

Figure 22. Reactive power of DG1 when the disturbance occurs at $\mathrm{V}_{2}$

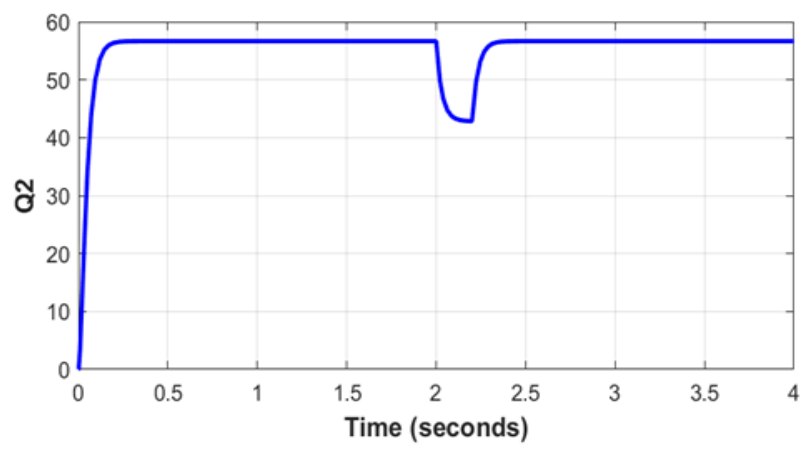

Figure 23. Reactive power of DG3 when the disturbance occurs at $\mathrm{V}_{2}$

\section{CONCLUSION}

In this paper, a nonlinear state-space model of a microgrid was presented. The model included the most important dynamics. This modeling method could be extended to n-generators. The model was analyzed by means of both stability study of Lyapunov function and root locus plot. A general methodology to find a valid Lyapunov function for nonlinear stability analysis was presented. By using that Lyapunov function, the region of asymptotic stability can be determined. These tools will allow designing microgrid systems with loads, generators, and storage systems, hence global stability of the system.

\section{REFERENCES}

[1] A. Madureira and J. A. Lopes, "Coordinated Voltage Support in Distribution Networks with Distributed Generation and Microgrids," Renewable Power Generation IET, vol. 3, pp. 439-454, 2010, doi: 10.1049/iet-rpg.2008.0064. 
[2] P. Vovos, A. Kiprakis, A. R. Wallace, and G. Harrison, "Centralized and Distributed Voltage Control: Impact on Distributed Generation Penetration," IEEE Transactions on Power Systems, vol. 22, pp. 476-483, 2007, doi: 10.1109/TPWRS.2006.888982.

[3] Z. H. Saleh, Z. H. Ali, R. W. Daoud, and A. H. Ahmed, "A study of voltage regulation in microgrid using a DSTATCOM," Bulletin of Electrical Engineering and Informatics (BEEI), vol. 9, no. 5, pp. 1766-1773, 2020, doi: 10.11591/eei.v9i5.2442.

[4] N. K. Choudhary, S. R. Mohanty, and R. K. Singh, "Power Management in Microgrid: Analysis in Grid Connected and Islanded Mode of Operation," International Journal of Applied Power Engineering (IJAPE), vol. 6, no. 3, pp. 160-170, 2017.

[5] J. Guerrero, L. Vicuna, J. Alcala, M. Castilla, and J. Miret, "A Wireless Controller to Enhance Dynamic Performance of Parallel Inverters in Distributed Generation Systems," IEEE Transactions on Power Electronics, vol. 19, pp. 1205-1213, 2004, doi: 10.1109/TPEL.2004.833451.

[6] D. Ariyasinghe and D. Vilathgamuwa, "Stability Analysis of Microgrids with Constant Power Loads," 2008 IEEE International Conference on Sustainable Energy Technologies, 2008, pp. 279-284.

[7] N. Soni, S. Doolla, and M. C. Chandorkar, "Analysis of Frequency Transients in Isolated Microgrids," in 2016 IEEE Industry Applications Society Annual Meeting, 2016, pp. 1-9 .

[8] R. Arulmurugan, "Design and testing of stability improvement of nine multi-level H-inverter for distribution system," International Journal of Robotics and Automation (IJRA), vol. 8, no. 4, pp. 245-255, 2019, doi: 10.11591/ijra.v8i4.pp245-255.

[9] R. Ashrafi, H. Abadi, and A. Nekoubin, "Improving Transient Stability in Power Systems by Using Fuzzy Logic Controlled SVC," International Journal of Robotics and Automation (IJRA), vol. 6, no. 4, pp. 227-233, 2017, doi: 10.11591/ijra.v6i4.pp227-233.

[10] M. M. A. Abdelaziz, H. E. Farag, and E. F. El-Saadany, "Optimum Droop Parameter Settings of Islanded Microgrids With Renewable Energy Resources," IEEE Transactions on Sustainable Energy, vol. 5, no. 2, pp. 434-445, 2014.

[11] D. K. Dheer, N. Soni, and S. Doolla, "Improvement of Small Signal Stability Margin and Transient Response in Inverter-Dominated Microgrids," Sustainable Energy, Grids and Networks, vol. 5, pp. 135-147, 2016, doi: 10.1016/j.segan.2015.12.005.

[12] C. L. Chen, J. S. Lai, D. Martin, and Y. S. Lee, "State-Space Modeling, Analysis, and Implementation of Paralleled Inverters for Microgrid Applications," 2010 Twenty-Fifth Annual IEEE Applied Power Electronics Conference and Exposition (APEC), Palm Springs, CA, USA 2010, pp. 619-626.

[13] N. Soultanis, S. Papathanassiou, and N. Hatziargyriou, "A Stability Algorithm for the Dynamic Analysis of Inverter Dominated Unbalanced LV Microgrids," Power Systems, IEEE Transactions on, vol. 22, pp. 294-304, 2007, doi: 10.1109/TPWRS.2006.887961.

[14] S. Iyer, M. Belur, and M. Chandorkar, "A Generalized Computational Method to Determine Stability of a Multiinverter Microgrid," Power Electronics, IEEE Transactions on, vol. 25, pp. 2420-2432, 2010, doi: 10.1109/TPEL.2010.2048720.

[15] Y. Du, X. Lu, J. Wang, and S. Lukic, "Distributed Secondary Control Strategy for Microgrid Operation with Dynamic Boundaries," IEEE Transactions on Smart Grid, vol. 10, no. 5, pp. 5269-5282, 2019, doi: 10.1109/TSG.2018.2879793.

[16] R. Pérez-Ibacache, C. A. Silva, and A. Yazdani, "Linear State-Feedback Primary Control for Enhanced Dynamic Response of AC Microgrids," IEEE Transactions on Smart Grid, vol. 10, pp. 3149-3161, 2019.

[17] H. R. Najafi and F. Dastyar, "Dynamic Modeling of Autonomous Wind-Diesel system with Fixed-Speed Wind Turbine," International Journal of Applied Power Engineering (IJAPE), vol. 1, no. 2, pp. 47-64, 2012.

[18] H. Afianti, O. Penangsang, and A. Soeprijanto, "Stability and reliability of low voltage hybrid AC-DC microgrids power flow model in islanding operation," Indonesian Journal of Electrical Engineering and Computer Science (IJEECS), vol. 19, no. 1, pp. 32-41, 2020.

[19] M. M. Alam, C. Moreira, M. R. Islam, and I. M. Mehedi, "Continuous Power Flow Analysis for Micro-Generation Integration at Low Voltage Grid," in 2019 International Conference on Electrical, Computer and Communication Engineering (ECCE), 2019, pp. 1-5.

[20] I. Sofimieari, M. Wazir, and F. Obite, "Modelling and analysis of a PV/wind/diesel hybrid standalone microgrid for rural electrification in Nigeria," Bulletin of Electrical Engineering and Informatics (BEEI), vol. 8, no. 4, pp. 1468-1477, 2019, doi: 10.11591/eei.v8i4.1608

[21] I. Alhamrouni, W. Wahab, M. Salem, N. Rahman, and L. Awalin, "Modeling of Micro-grid with the consideration of total harmonic distortion analysis," Indonesian Journal of Electrical Engineering and Computer Science (IJEECS), vol. 15, no. 2, pp. 581-592, 2019.

[22] N. Pogaku, M. Prodanovic, and T. C. Green, "Modeling, Analysis and Testing of Autonomous Operation of an Inverter-Based Microgrid," IEEE Transactions on Power Electronics, vol. 22, no. 2, pp. 613-625, 2007, doi: 10.1109/TPEL.2006.890003.

[23] E. Barklund, N. Pogaku, M. Prodanovic, C. Hernandez-Aramburo, and T. C. Green, "Energy Management in Autonomous Microgrid Using Stability-Constrained Droop Control of Inverters," IEEE Transactions on Power Electronics, vol. 23, no. 5, pp. 2346-2352, 2008.

[24] A. Apostolov, J. Appleyard, A. Elneweihi, R. Haas, and G. W. Swift, “Transformer Protection,” Power System Stability and Control, in L. L. Grigsby, (Ed.), The Electric Power Engineering Handbook. New York, USA: CRC Press, pp. 1-11, 2007. 
[25] E. A. A. Coelho, P. C. Cortizo, and P. F. D. Garcia, "Small Signal Stability for Parallel Connected Inverters in Stand-Alone AC Supply Systems," Conference Record of the 2000 IEEE Industry Applications Conference. ThirtyFifth IAS Annual Meeting and World Conference on Industrial Applications of Electrical Energy, 2000, vol. 4, pp. 2345-2352.

[26] G. Díaz, C. Gonzalez-Moran, J. Gómez-Aleixandre, and A. Diez, "Complex-Valued State Matrices for Simple Representation of Large Autonomous Microgrids Supplied by PQ and V f Generation," IEEE Transactions on Power Systems, vol. 24, pp. 1720-1730, 2009, doi: 10.1109/TPWRS.2009.2030396.

[27] H. K. Khalil, "Input-Output Stability," in Nonlinear Systems, New Jersey, USA, Prentice Hall, pp. 200-225, 1996.

[28] A. Bacciotti and L. Rosier, "Liapunov Functions and Stability in Control Theory," Springer-Verlag Berlin Heidelberg, pp. 27-80, 2005.

\section{BIOGRAPHIES OF AUTHORS}

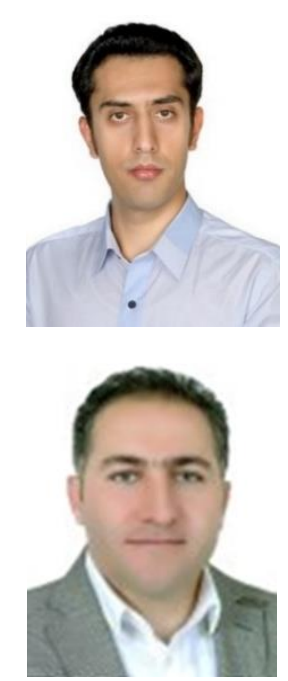

Hamed Ahmadi received the B.Sc. degree from University of Kurdistan, Sanandaj, Iran, and the M.Sc. degree from Amirkabir University, Tehran, Iran, both in Electrical Engineering in 2009 and 2011, respectively. He is working toward the Ph.D. degree in control of power systems at the University of Kurdistan, Iran. His research interests include Microgrid dynamics and control, robust, predictive and nonlinear control for application of power electronics in distributed systems.

Qobad Shafiee received PhD degree in electrical engineering from the Department of Energy Technology, Aalborg University (Denmark) in 2014. He is currently an Assistant Professor, Associate Director of International Relations, and the Program Co-Leader of the Smart/Micro Grids Research Center at the University of Kurdistan, Sanandaj, Iran, where he was a lecturer from 2007 to 2011. In 2014, he was a Visiting Scholar with the Electrical Engineering Department, the University of Texas at Arlington, Arlington, TX, USA. He was a PostDoctoral Fellow with the Department of Energy Technology, Aalborg University in 2015. His current research interests include modeling, energy management, control of power electronicsbased systems and microgrids, and model predictive and optimal control of modern power systems.

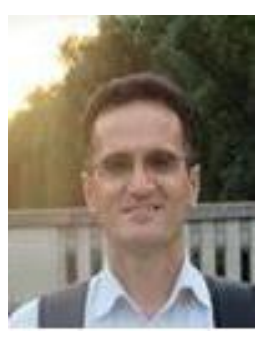

Hassan Bevrani received PhD degree in electrical engineering from Osaka University (Japan) in 2004. Currently, he is a full professor and the Program Leader of Smart/Micro Grids Research Center (SMGRC) at the University of Kurdistan (UOK). From 2016 to 2019 he was the UOK vice-chancellor for research and technology. Over the years, he has worked as senior research fellow and visiting professor with Osaka University, Kumamoto University (Japan), Queensland University of Technology (Australia), Kyushu Institute of Technology (Japan), Centrale Lille (France), and Technical University of Berlin (Germany). Prof. Bevrani is the author of 6 international books, 15 book chapters, and more than 300 journal/conference papers. His current research interests include smart grid operation and control, power systems stability and optimization, Microgrid dynamics and control, and Intelligent/robust control applications in power electric industry. 